\title{
Towards the Design of a Virtual Heritage Experience Based on the World-as-Support Interaction Paradigm
}

Marie-Monique Schaper

Maria Santos

Laura Malinverni

Narcis Pares

Universitat Pompeu Fabra

C/ Roc Boronat 138, 08018

Barcelona, Spain

mariemonique.schaper@upf.edu

msantosbaranco@gmail.com

laura.malinverni@upf.edu

narcis.pares@upf.edu

Paste the appropriate copyright/license statement here. ACM now supports three different publication options:

- ACM copyright: ACM holds the copyright on the work. This is the historical approach.

- License: The author(s) retain copyright, but ACM receives an

exclusive publication license.

- Open Access: The author(s) wish to pay for the work to be open access. The additional fee must be paid to ACM.

This text field is large enough to hold the appropriate release statement assuming it is single-spaced in Verdana 7 point font. Please do not change the size of this text box.

Each submission will be assigned a unique DOI string to be included here.

\begin{abstract}
We present the initial design stage of a Virtual Heritage experience for a bomb shelter built during the Spanish Civil War, namely Refugi 307. The shelter currently belongs to the History Museum of the city which provides guided tours through the cultural heritage site for schools and the general public. The aim of the study was to define the requirements for the design of a first prototype based on the World-as-Support interaction paradigm. We conducted an ethnographic study and Participatory Design (PD) to analyze different aspects of the requirements and to include multiple needs and viewpoints of the involved stakeholders. Based on the outcomes, we outline potential for activities to foster

(1) contextual-awareness between the learning content and the shelter site, (2) environment-awareness in relation to missing objects in the physical space and (3) social-awareness to embody feelings related to solidarity and empathy.
\end{abstract}

\section{Author Keywords}

Augmented Reality; Virtual Heritage; World-as-Support Paradigm; Learning; Participatory Design; Children. 


\section{ACM Classification Keywords}

H.5.2. Information interfaces and presentation (e.g., $\mathrm{HCI}$ ): User Interfaces; Interaction styles.

\section{Introduction}

Cultural heritage sites play a crucial role in how people understand history and culture. According to Betsworth et al. [2] they have "the potential to teach us important lessons, such as where we came from and subsequently, the people it has made us today". Interactive experiences for these contexts are commonly used to complement learning concepts rather than being considered as independent learning tools $[5,13,14]$. To achieve this, a wide range of screen-based technology approaches have been explored in museums [16] and cultural heritage $(\mathrm{CH})$ sites [17-19]. The interaction with multimedia content allows visitors to obtain a better understanding, e.g. of people living in past cultures [9]. Through virtual and augmented reality, hidden experiences or vanished aspects of the site are highlighted $[8,15]$.

However, technologies which support screen-based interfaces, such as smartphones or tablets, tend to draw user attention away from the physical space onto a framed window which tends to isolate and provide an individual experience. Hence, the employed technology can become a distraction or even the main focus of the visit. In this context, Müller et al. [12] analyzed users' behavior in a collaborative task with a tablet-based AR application. The authors pointed out that almost no participants paid attention to the physical environment during the experience. Betsworth et al. [2] described how, in the act of holding the screen-based device in front of the physical world, the system became a "digital divider". In other words, when using screen- based devices (e.g. in museums) visitors perceive the world which surrounds them and the displayed multimedia content through a "digital window". Consequently, the user's focus may shift from the interest and interaction with the physical environment and other visitors, to an isolated screen-based experience. On the other hand, the design of interactive experiences for non-standard museum spaces [23], such as archaeological sites, is particularly challenging. These site-specific spaces often cannot be modified by adding physical objects or installations. Therefore, they acquire their importance and meaning through their situatedness; i.e. the meaning of their historical context is provided by the fact that the visitor is actually physically present on site. Such visits are often complemented by guided tours to direct visitors' attention towards aspects that are not necessarily obvious without further explanations. Nevertheless, visitors still need to imagine missing artifacts, people living during that period, or related events. Due to limited knowledge and the lack of previous experiences, it may be particularly difficult for children to imagine some of these contents and situations.

To address these challenges, we present the design process of a preliminary prototype using an emerging interaction design paradigm, named the World-asSupport (WaS) [11], in the context of a site-specific learning experience for a $\mathrm{CH}$ site. This paradigm is based on projective AR; i.e. augmentation is achieved by projecting the digital content on the physical world surrounding the user via a handheld device. This portable system based on a pico-projector and a mobile device, dynamically recognizes the surrounding physical world (i.e. topography, objects, users, and motion) and projects the context-aware digital information directly 


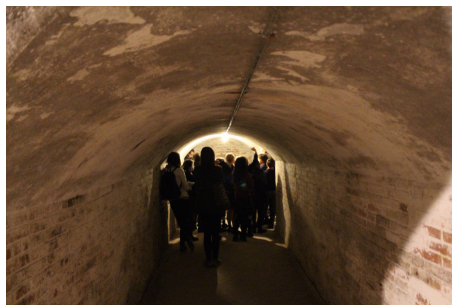

Figure 1: A school class visiting the guided tour of the cultura heritage site Refugi 307

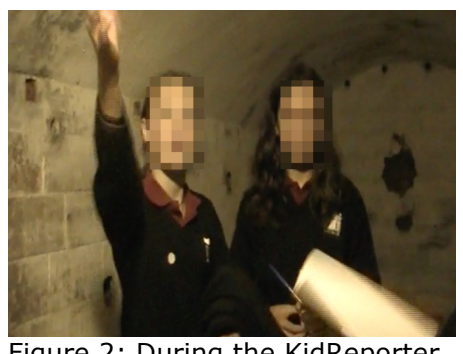

Figure 2: During the KidRepo technique children expressed their interests towards certain places in the shelter. onto it [1]. This allows interaction designers to take advantage of the benefits of Reality-Based Interaction, such as environment awareness and social awareness [7]. Moreover, as users act within the physical world to interact with digital content [4], it affords the potential of bodily and tangible interaction such as tangible manipulation, spatial interaction and embodied facilitation [6].

We now explain the initial design stage of a Virtual Heritage (VH) experience for a non-standard museum space. The aim of our study was to define the requirements for the design of a first prototype based on the WaS interaction paradigm. We conducted an ethnographic study and Participatory Design (PD) process to analyze the requirements and to include the needs and viewpoints of the involved stakeholders, namely: $5^{\text {th }}$ grade children, museum and education experts, and guides. Based on the outcomes, we then define and describe the specific educational goals for the augmented, full-body interactive, non-formal learning experience that complements the guided tour.

\section{Designing the VH experience}

Our study was carried out in the context of a $\mathrm{CH}$ location, namely Refugi 307. The site is one of the 1,402 bomb shelters that were built by civilians during the Spanish Civil War in Barcelona aimed at protecting the population. The shelter is nowadays part of the History Museum of the city which provides guided tours through the cultural heritage site to schools and the general public. It consists of an almost empty and twisting tunnel 200 meters long (Figure 1). Visitors can get an impression of the living conditions during the Spanish Civil War and some facilities inside such as benches, an infirmary, a children's room, and a fireplace. The walls and ceiling of the shelter show traces of objects from the past (e.g. the origina lighting system, signs with instructions on behavior rules, holes to fix stretchers to the wall, etc.) that were once installed inside. Poor light conditions and high humidity in the shelter limit the possibilities to permanently install multimedia systems in the physical space.

In order to gather requirements from the different stakeholders, we carried out (1) three project meetings with two museum and education experts, (2) interviews with three tour guides and four teachers from three different local schools that visited the Refugi 307 with their class, (3) guided tours with two school classes and (4) two PD sessions with each of them.

Procedure of Participatory Design Workshop

In the study participated a total of 40 children (girls = 18 ; boys $=22$; age mean $=10.78$ years old $)$. The first session lasted for 180 minutes (120 minutes guided tour in the shelter and 30 minutes PD activities). After the visit to the shelter, we divided the children into groups of 3-4 members and instructed them in an activity based on the KidReporter technique [28]. Each group was asked to record a 2-minute video on the place in the shelter they found most interesting (Figure 2 ). Therefore, we handed out a map of the shelter and gave each group 10 minutes to choose one place of interest and to brainstorm how they would perform the interview.

The second session held in the school also lasted for 180 minutes. The children were again divided into the same groups. Using the maps of the shelter, they were asked to indicate and explain the places that they 


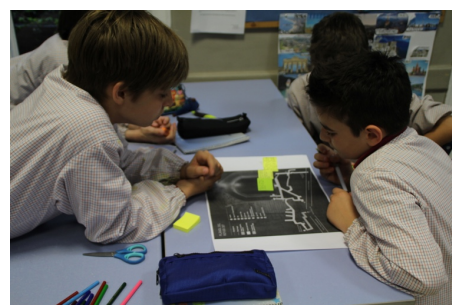

Figure 3: Children indicated on maps of the shelter the aspects which they remembered and had caught their attention during the guided tour.

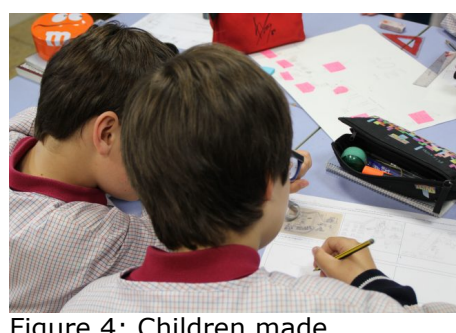

Figure 4: Children made storyboards about events during the Spanish Civil War.

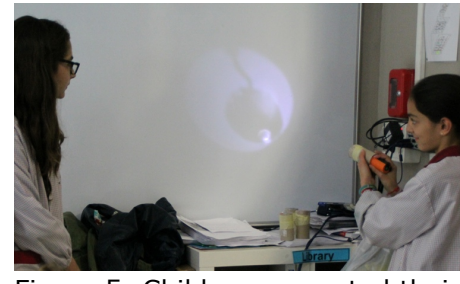

Figure 5: Children presented their ideas for the improvements for the guided tour using a low-tech prototype. remembered and that had caught their attention the most (Figure 3). The children wrote their comments on post-it notes and placed them on the map. We interviewed each group individually during the activity.

After that, each child received a different storyboard template. The first scene was already filled out with a drawing made by children during the Spanish Civil War (Figure 4). They were encouraged to think of a narrative related to the presented drawing. The aim of this activity was to evaluate children's interests and personal values in relation to the learning topic.

Subsequently, the children were instructed to re-design the guided tour according to their own interests and preferences. We first explained our interactive technology approach to them (the WaS paradigm) based on pico-projectors to augment the physical space with projected digital content. The children were then asked to produce low-tech prototypes we called "spotlights"; i.e. the children drew on transparent plastic and placed them over one end of a paper roll which had a flashlight inside (Figure 5). This simulated the projection capabilities of the final handheld device. Finally, each group gave a 5-minute presentation to explain and enact their ideas with the low-tech prototype. During all PD activities, we recorded short video interviews with each group while they were working on their proposals. The aim was to capture their different ideas and reflections during the design process.

\section{Analysis}

During the activities, two researchers took notes and all interviews and sessions were video recorded. Subsequently, the video was transcribed using a descriptive format focusing on experts and children's verbal expressions and behavior. The analysis was carried out through a grounded approach [3]. The goals of the analysis were to identify (1) experts' educational goals and (2) children's interests, understanding, core meanings and misconceptions related to the learning topic. From the data collected, key points were marked and coded, and then extracted from the text. The codes were grouped into similar concepts and finally categories were formed. Two researchers performed the analysis. After a process of individual coding, a common agreement was reached through a number of meetings.

\section{Results}

Educational Goals: The findings from the interviews with educational experts from the museum and school determined that one of the main goals of the interactive experience should be to foster children's competence in understanding the relation between historical events from the Spanish Civil War and similar contemporary conflicts occurring today (e.g. the civil war in Syria). This aim involved strengthening the feeling of solidarity and empathy with people who have suffered and/or are still suffering war. To offer children emotional anchors to the learning topic, the content of the experience had to link to situations they can relate to their own identity; e.g. family members from previous generations or children in war zones in other countries.

Children's Interest and Understanding: The results of the ethnographical study indicated that the children were very engaged during the guided tour. They asked many questions about details of the explained content. Some children got very excited about being in the 


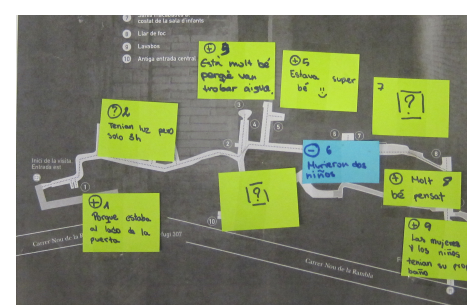

Figure 6: This group was particularly interested in the water fountain and the power generator. The children expressed their sadness about the accident in the children's room. They also expressed curiosity towards parts of the shelter that were not included in guided tour.

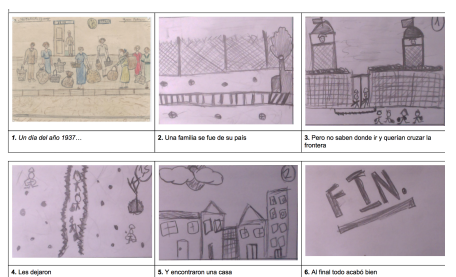

Figure 7: A child explained in her story how a family had to leave their home and finally found a

"happy" life in another country. shelter. Other children felt uncomfortable due to physical conditions of the shelter (e.g. darkness, low temperature, or humidity). During the visit, they had many opportunities to "embody" past events; e.g. while sitting on benches just like civilians did during bomb attacks eighty years back.

During the Kidreporter activity, 6 out of 10 groups chose to perform the interview on the infirmary. They focused on the fact that it was located in the middle of the tunnel and hence the safest place in the shelter. They expressed the importance to have a place where injured people could be treated. Three groups performed an interview on the fire place. They found it interesting first, because the place has a chimney and ventilation system built into the stone of the mountain under which the shelter was built. Second, despite the harsh conditions in the shelter, a family from the South of Spain lived in it for ten years during the post-war period. Third, a man used the shelter to illegally grow mushrooms on the walls. Only one group performed an interview on the children's room. They expressed their sadness about the collapse of the ceiling during a bombing attack which injured two children. These findings suggest the children were particularly interested in content related to values such as safety, caring for each other, family and personal fate.

During the map activity (Figure 6) in class, in addition to the previously presented places, all ten groups reported on at least one other location related to people's basic needs: toilets ( 9 out of 2 groups), a water fountain ( 8 groups), and a power generator for the lighting system ( 3 groups). Also, one group mentioned that they were interested to see the original signs on behavior rules; another group asked for images of bombs and shrapnel; and two groups expressed their curiosity about tunnel segments that were not included in the guided tour. The results of this activity revealed that the children showed a high interest in civilian's living conditions in the shelter. Furthermore, they point towards the need of visualizing missing and hidden artifacts in the physical space.

The storyboard activity helped us to get deeper insights on children's cultural values. For instance, the children reported on the harsh living conditions during the war. Four children wrote their stories about the lack of food and how people had to find provisions to survive. One child wrote about men who went to the frontlines. Another child mentioned that people had lost their houses. Two children explained how people were forced to leave their country. However, many of these stories had a "happy end", i.e. as soon as the war ended everything went back to "normal" (Figure 7). The results indicate that the children were not conscious about long-term effects cause by the war.

Children's main misconceptions across the different activities were related to the expectations of finding weapons in the shelter from people who tried to protect their family against Dictator Franco's army (6 children). In other words, they did not understand that the shelter represented a "passive" form of defense, in contrast to the "active" defense that involved using weapons.

Ideas for improvements of guided tour: The children proposed, e.g. (1) a treasure hunt activity with hints to provide a playful experience during the guided tour, (2) to explain the guided tour through pictures, (3) an activity where children could dig up the destroyed children's room and discover what was hidden under 
the stones, (4) to perform a drill of the bomb alarm and experience the rushing of people into the shelter. Thus, Children's proposals revealed a need for participative and hand-on activities during the guided tour.

\section{Requirements for the prototype}

Our approach helped us to define key requirements for the design of a full-body interactive $\mathrm{VH}$ learning experience for this $\mathrm{CH}$ site. Our observations confirmed that the guided tour had already a high educational potential in introducing the learning topic to the children. However, we saw several opportunities to complement it through a $\mathrm{VH}$ experience based on the WaS interaction paradigm. We suggest that the use of the novel paradigm by taking advantage of children's situatedness and combining this experience with augmentation of hidden contents and specific interactions in the physical space could support their meaning making process of the learning contents. We propose to integrate the following types of activities into the learning experience during the guided tour.

- Context-aware AR activities through location-based projections of audiovisual material on historical events (e.g. a testimonial of a woman who volunteered as a nurse can only be projected in the infirmary). Having multiple location-based events allows presenting content from different perspectives and comparing them. These activities could help children to understand changes in society, different standpoints upon historical events (e.g. active vs. passive defense), and long-term effects of the civil war (e.g. collective trauma).

- Environment-aware AR activities through projections based on surface and object recognition to represent missing content at their original locations (e.g. the signs of behavior rules can be projected on the empty holes on the walls). These activities may facilitate children to imagine objects they have never been in contact with.

- Social-aware AR activities through projections of multiple pieces of content and a common task (e.g. two children project one piece each of a larger image that together represents a stretcher. They have to move their images in a synchronized way to bring an injured person safely to the infirmary). By performing similar action to those performed by civilians during the war, children could perceive, for example, the notion of physical effort [10]. These activities could help children to understand feelings of solidarity and empathy of people in these situations.

\section{Conclusions}

In this paper, we have described the initial design stage aimed at gathering requirements for a full-body interactive $\mathrm{VH}$ learning experience. The results allowed us to formulate concrete activities fostering (1) contextual-awareness between the learning content and the shelter, (2) environment-awareness in relation to missing objects in the physical space and (3) socialawareness as support for understanding feelings such as solidarity and empathy. These activities were recently implemented in a first low-tech prototype based on the World-as-Support paradigm. We are currently exploring its potential and limitations in the contexts of cultural heritage sites and other learning contexts [11].

\section{Acknowledgements}

Supported by the Spanish Ministry of Economy and Competitiveness (Grant TIN2014-60599-P). 


\section{References}

1. Ronald Azuma, Yohan Baillot, Reinhold Behringer, Steven Feiner, Simon Julier, and Blair MacIntyre. 2001. Recent advances in augmented reality. IEEE computer graphics and applications 21, 6: 34-47.

2. Liam Betsworth, Huw Bowen, Simon Robinson, and Matt Jones. 2014. Performative technologies for heritage site regeneration. Personal and Ubiquitous Computing 18, 7: 1631-1650.

http://doi.org/10.1007/s00779-014-0766-3

3. Juliet M. Corbin and Anselm Strauss. 1990.

Grounded theory research: Procedures, Canons and Evaluative Criteria. Qualitative sociology 13, 1: 3-21.

4. Paul Dourish. 2001. Where the Action Is: The Foundations of Embodied Interaction. Where the action is the foundations of embodied interaction $36,233$.

http://doi.org/10.1162/leon.2003.36.5.412

5. Bernadette Flynn. 2013. v-Embodiment for cultura heritage. Digital Heritage International Congress, IEEE, 347-354.

http://doi.org/10.1109/DigitalHeritage.2013.67437 59

6. Eva Hornecker and Jacob Buur. 2006. Getting a grip on tangible interaction: a framework on physical space and social interaction. Proceedings of the SIGCHI conference on Human Factors in computing systems, ACM, 437-446.

7. Robert J.K. Jacob, Audrey Girouard, Leanne M. Hirshfield, et al. 2008. Reality-based interaction: a framework for post-WIMP interfaces. Proceedings of the SIGCHI conference on Human factors in computing systems, ACM, 201-210.

8. Sarah Kenderdine, Leith K. Y. Chan, and Jeffrey Shaw. 2014. Pure Land: Futures for Embodied Museography. Journal on Computing and Cultural Heritage 7, 2: 1-15.

http://doi.org/10.1145/2614567

9. Stelios Kourakis, Cakir Aker, and Narcis Pares. 2012. We hunters: Interactive communication for young cavemen. International Journal of Arts and Technology 5, 2-4: 199-220.

http://doi.org/10.1145/1810543.1810554

10. Leilah Lyons, Brian Slattery, Priscilla Jimenez, Brenda Lopez, and Tom Moher. 2012. Don't forget about the sweat: Effortful embodied interaction in support of learning. Proceedings of the Sixth International Conference on Tangible, Embedded and Embodied Interaction - TEI '12, ACM, 77-84. http://doi.org/10.1145/2148131.2148149

11. Laura Malinverni, Julian Maya, Marie-Monique Schaper, and Narcis Pares. 2017. The World-asSupport: Embodied Exploration, Understanding and Meaning-Making of the Augmented World.

Proceedings of the 2017 CHI Conference on Human Factors in Computing Systems (CHI '17)., ACM. http://doi.org/http://dx.doi.org/10.1145/3025453. 3025955

12. Jens Müller, Roman Rädle, and Harald Reiterer. 2016. Virtual Objects as Spatial Cues in

Collaborative Mixed Reality Environments: How They Shape Communication Behavior and User Task Load. Proceedings of the $2016 \mathrm{CHI}$ Conference on Human Factors in Computing Systems (CHI '16)., ACM, New York, NY, USA 1245-1249.

http://doi.org/http://dx.doi.org/10.1145/2858036. 2858043

13. Eva Pietroni, Christie Ray, Claudio Rufa, Daniel Pletinckx, and Iefke Van Kampen. 2012. Natura interaction in VR environments for Cultural

Heritage and its impact inside museums: The Etruscanning project. Proceedings of the 2012 18th International Conference on Virtual Systems and Multimedia, VSMM 2012: Virtual Systems in the Information Society, IEEE, 339-346.

http://doi.org/10.1109/VSMM.2012.6365943

14. Christie A. Ray and Merel van der Vaart. 2013 Towards an integrative approach to interactive museum installations. Proceedings of the DigitalHeritage 2013 - Federating the 19th Int'l VSMM, 10th Eurographics GCH, and 2nd UNESCO 
Memory of the World Conferences, Plus Special Sessions fromCAA, Arqueologica 2.0 et al., IEEE, 701-704.

http://doi.org/10.1109/DigitalHeritage.2013.67448 39

15. Maria Roussou and Michalakopoulou Ave. 2007.

Children Designers in the Museum: Applying Participatory Design for the Development of an Art Education Program. Proceedings of the 6th

international conference on Interaction design and children: $77-80$.

http://doi.org/10.1145/1297277.1297292

16. Maria Roussou, Laia Pujol, Akrivi Katifori, Angeliki Chrysanthi, Sara Perry, and Maria Vayanou. 2015. The museum as digital storyteller: Collaborative participatory creation of interactive digital experiences. MW2015: Museums and the Web 2015. Retrieved November 19, 2015 from http://mw2015.museumsandtheweb.com/paper/th e-museum-as-digital-storyteller-collaborativeparticipatory-creation-of-interactive-digitalexperiences/

17. Mona Sakr, Carey Jewitt, and Sara Price. 2016 Mobile Experiences of Historical Place: A

Multimodal Analysis of Emotional Engagement. Journal of the Learning Sciences 25, 1: 51-92. http://doi.org/10.1080/10508406.2015.1115761

18. Laura Serra Oliva, Anna Mura, Alberto Betella, Daniel Pacheco, Enrique Martinez, and Paul Verschure. 2015. Recovering the history of Bergen Belsen using an interactive $3 \mathrm{D}$ reconstruction in a mixed reality space the role of pre-knowledge on memory recollection. Digital Heritage, 163-165. http://doi.org/10.1109/DigitalHeritage.2015.74138 60

19. K.a Daikoku T.b Kusunoki F.c Inagaki S.b Takenaka M.d Hayashi T.a Yano M.e Tarumi H.a Yamada. 2009. KEI-Time Traveler: A Virtual Time Machine with Mobile Phones for Learning Local History. In Transactions on Edutainment II. Springer, Berlin, Heidelberg, pp 258-281.

http://doi.org/10.1007/978-3-642-03270-7_18 